\title{
First-Degree Burn
}

National Cancer Institute

\section{Source}

National Cancer Institute. First-Degree Burn. NCI Thesaurus. Code C76130.

A painful injury to the epidermis due to chemical, friction, radiation or thermal exposure.

The affected area appears red and blanches when touched. 